\title{
The Application of Campus Wireless Network Based CRS in Large Teaching Classes
}

\author{
Mantao Wang ${ }^{1, a}$, Xuliang Duan ${ }^{1, b^{*}}$, Jong Mu ${ }^{1, c}$, Qiang Huang ${ }^{1, d}$ \\ ${ }^{1}$ College of Information and Engineering, Sichuan Agricultural University, 625014, China \\ awangmantao@126.com, b1076092539@qq.com, cscmjmj@yahoo.com.cn, \\ dscmjmj@yahoo.com.cn \\ *The corresponding author
}

Keywords: Campus wireless network; CRS system; Teaching quality; Large teaching classes

\begin{abstract}
Due to various objective reasons, large teaching classes are very common in college education and seriously affect the teaching quality. In order to improve the teaching quality of large teaching classes, we introduced the CRS system which is based on campus wireless network to improve teaching interaction. Practical application shows that the CRS could strengthen the interaction and remove information bottlenecks between teachers and students. The CRS helps teachers to construct the scientific evaluation system and enhance the monitoring of teaching quality.
\end{abstract}

\section{Introduction}

Under the background of the informationization tide sweeps across the whole world, in the field of education also in actively adapt to this trend. The traditional teaching mode is changing in classroom all over the world, such as the micro course, flipping the classroom, MOOC and so on [1]. For all that, due to the restriction of various factors, the traditional teaching mode and teaching means is still widespread in the actual teaching activities [2].

At present, China higher education facing scale expands and teacher shortage, in this case, large teaching classes in college is wide prevalence. The so-called large teaching classes, also called joint classes, that is, the original two or more classes of a course teaching merged into a large class. The large teaching classes improve the teachers' working efficiency and partly alleviate the teacher shortage problem, and also emerge a lot of practical problems.

\section{Current Situation of Large Teaching Classes}

Large class teaching is the most commonly used way teaching method, for most teachers, this is in use for a long time and simple way. But in terms of students, very often in the dreaming state; Meanwhile, some students listen carefully, under the limelight, embarrassed to ask questions and discuss teachers. These conditions in large class teaching process, can easily be hidden and ignored.

First of all, lecture method is the most common way in large teaching classes. Application of information technology generally only help teacher explaining and demonstrating in classroom, in the form of PPT, animation, audio and video files, etc., but not much help in constructing a teacher-student interaction classroom.

Secondly, due to the constraints of time and space in the large teaching classes, there is very little group discussion, cooperative learning, teacher-student role reversal, teacher-student interaction and so on, all these lead to the boring atmosphere and lack of learning enthusiasm in classroom.

Third, teacher cannot keep abreast of student learning in classroom. Although to-face Q\&A could help teacher partly understand students' learning performance, but it's hard to understand their overall learning situation.

Fourth, the evaluation mechanism is still not perfect. Currently, the students' final score usually includes usual performance and exam score, in large teaching class, it's hard for teacher to make a fair appraisal of student's usual performance. 
Fifth, due to the lack of effective supervision, teaching order is relatively chaos in large teaching classes. Teachers have to spend more time to maintain classroom discipline which reduces the efficiency of classroom teaching.

\section{Application of CRS System}

History of CRS Development. CRS (Classroom Response System) has experienced three generations. The first generation of CRS developed in 1980s, known as Classtalk. Limited by technical conditions, the classroom needs to install a specific cable network and software, the cost is very expensive. At the beginning of this century, the second generation CRS developed, which abandoned the original configuration of network and computer, began to use infrared technology (such as EduCue PRs and elnstruction CPS). In virtue of simple, stable and reliable, the 2rd generation CRS was widely use in basic and higher education. With the rapid development of wireless network and smart mobile devices, the third generation of CRS is beginning to develop. Based on wireless network, HTTP, Java, Microsoft. Net, various of smart mobile devices such as smartphones, laptops, tablet PC or PDA are connected into CRS. The devices have gradually become an organic part of classroom teaching facilities and inspire new vitality of CRS.

Eric Mazur research team in Harvard University organize group discussion and interactive teaching under the CRS supporting, improve students' learning efficiency and classroom participation. Students are regarded as the center, they take the scaffolding and cognitive conflict theory as the basic to design topics sequence of each knowledge point and induce students to think and discuss. The gratifying achievements have guiding significance for college teaching in China [3-9].

CRS Based on Campus Wireless Network. There is some commercial web based CRS software, such as Socmtive, polleverywhere, tophatmonoele and so on. Polleverywhere is mainly for business and education customer, while Socrative and tophatmonocle focus more on application in education. The above CRS system all can meet the teaching requirements in function, but for reasons such as high cost or network problem they often cannot be used well in practice.

Well performed wireless network covering the whole campus of Sichuan Agricultural University that which can meet the basic network demands of CRS. Based on existing research and the actual needs of teachers and students, we design a CRS for Sichuan Agricultural University. The system design is guided by the main idea of interaction and feedback in teaching, and the class teaching is divided into 3 stages: before class, during class and after class. Before class, teachers import the basic students information and tests into the system, and make the configuration of classroom response activities. During class, students and teacher are all involved to finish the whole teaching process. Teacher issues tests according designed activities, students recessive tests and submit answers. Teacher could check students' answers and feedback in time [10-12]. From the functional point of view, CRS can be divided into Teacher end and student end as shown in Fig. 1 and Fig. 2.

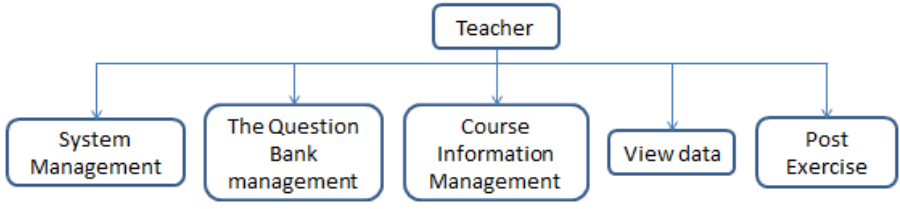

Figure 1. Function Diagram for Teacher

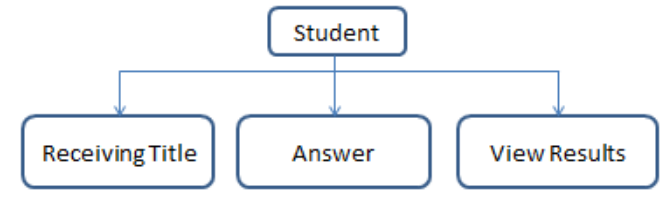

Figure 2. Function Diagram for Student

\section{Implementation Programs of CRS}

Under the support of CRS system, students who can provide feedbacks through smart devices for teacher are the subjects of learning. Meanwhile, teachers can not only get students' response in time but also obtain aggregated and analyzed data through CRS. Such interactions between teachers and students make the teaching process more effective and help to improve the students' learning 
enthusiasm and initiative. The specific implementation programs is as follows.

Before class:

1) Students provide student ID and smart phone number;

2) Teachers import teaching class information into CRS from educational management system and initialize the basic configuration;

3) According teaching program, teachers design classroom exercises and input them into CRS. The exercises can be in the form of radio, multiple choice and true or false questions.

During class:

1) In class teaching, teacher publish exercises according teaching needs; Students use smart phones to enter the CRS and answer.

2) Students need to finish their exercises and submit answers. CRS will automatically make judgment and provide immediate feedback to students.

3) Teacher close the current round of test and ready to make assignment.

4) Teacher assess the test result by statistics of exercises. Teacher could make some adjustment to teaching strategies and progress according to the feedback.

After class:

1) After the end of the course, the CRS provide statistical data. The data could be one indicator of student learning assignment, or can be used to analysis teaching difficulties and so on.

\section{Analysis on Teaching Effect of CRS}

Improve Teaching Management Level. In traditional large teaching classes, it's hard to check student's attendance. While CRS solve the above problems effectively. Take the compiler theory course teaching for example, after using CRS, the attendance rate increase from $87 \%$ to $97 \%, 10 \%$ higher than before, and learning atmosphere in classroom also has a great improvement.

Improve Learning Effect. There are two teaching classes of compiler theory course for computer major students, one is 2012 grade teaching class which is without supporting of CRS, and the other is 2013 grade teaching class which introduced CRS. Fig. 3 shows the comparison result of two teaching classes.

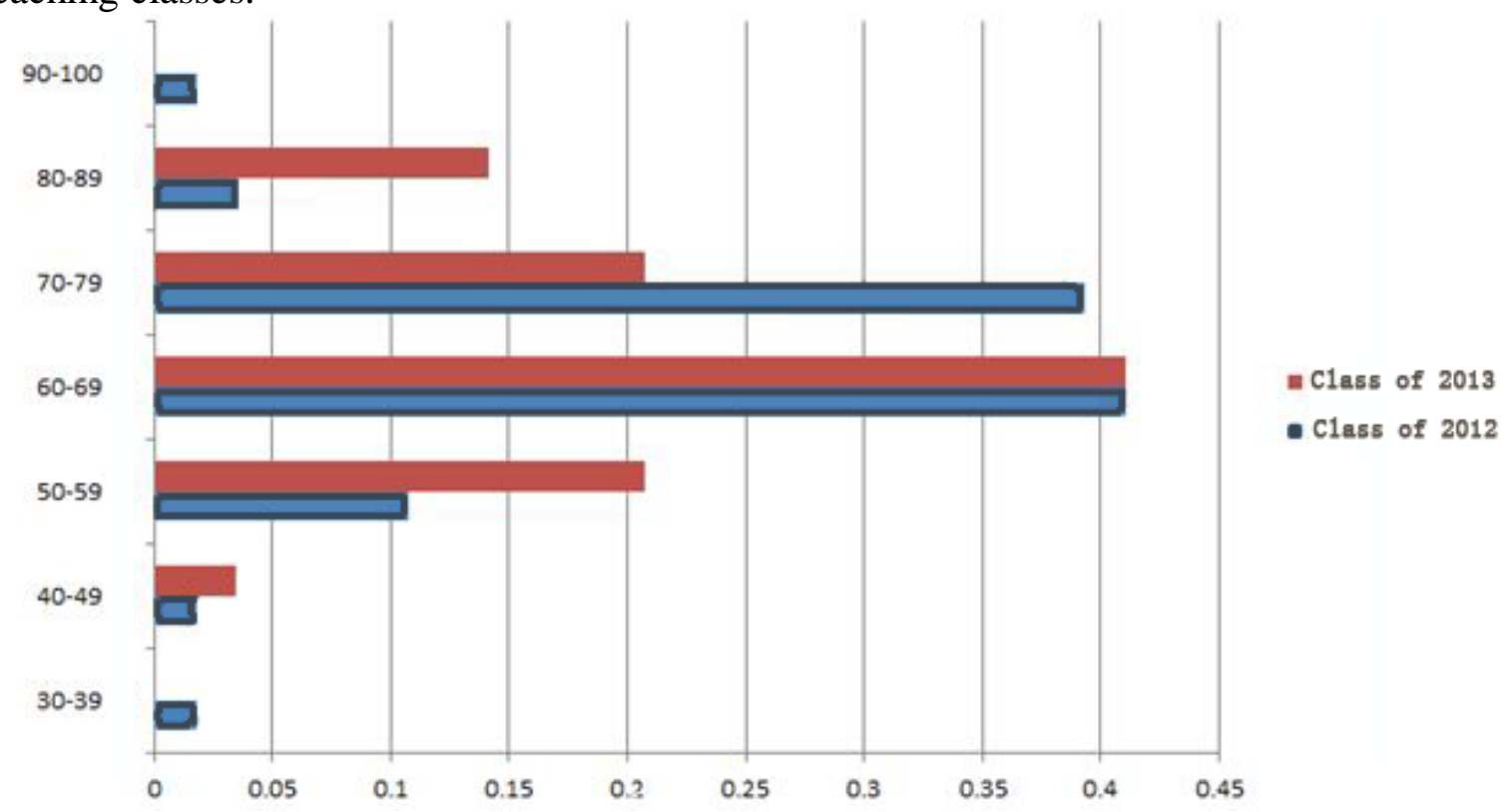

Figure 3. 2012 and 2013 compiler theory grade distribution

The 0-100 in centesimal system is divided into three levels as shown in Table 1, [0-59] indicates poor, [60-79] indicates general and [80 - 100] excellent. Statistical data show that the poor grade is 
reduced by $18 \%$ percent, general grade upgrade to $80 \%$, while the excellent grade decline by $8 \%$. As for the declaration rate in excellent grade, we suppose the reason may be that some students who perform excellent in traditional learning mode is not adapt to the new challenges in CRS teaching. However, it can be seen that the overall performance of the teaching class has been significantly improved.

Table 1 Each Score Proportion of Grade 2012 and 2013

\begin{tabular}{|c|c|c|}
\hline Score range & Class of 2012 & Class of 2013 \\
\hline $0-59$ & $24 \%$ & $14 \%$ \\
\hline $60-79$ & $62 \%$ & $80 \%$ \\
\hline $80-100$ & $14 \%$ & $6 \%$ \\
\hline
\end{tabular}

Investigation of CRS Application. In addition, a questionnaire survey was conducted to analyze effectiveness of CRS application. The questionnaire mainly includes student's attention, participation, interest and knowledge etc. All 163 questionnaires were distributed and returned 151 valid samples. The following is part of the problem and the results of the survey:

1) Is there any other classes that use CRS before? $100 \%$ of the students response that they didn't ever use a similar system, it shows that the form of interaction and feedback using CRS is novel.

2) Is the application of CRS help you concentrate attention on learning? About $85 \%$ of the students surveyed response that the introduction of CRS has a strong incentive effect on learning and it's helpful on improving learning attention.

3) Compared with the traditional classroom, do you prefer the new form? $88 \%$ of the surveyed students are willing to accept this teaching model, and there are also $3 \%$ do not like this teaching model because of "feeling controlled".

4) Is the guidance timely and effective? Is it enough interesting for you? Most students accept the guidance and can carry on effective learning, meanwhile some students consider the tests are relatively simple.

5) Are the teaching methods in CRS helpful for acquiring knowledge? There are over $90 \%$ students confirm that the CRS is helpful for learning in class.

Through the investigation, it can be seen that the CRS is a novel, easy to accept teaching method. In CRS, feedback and interaction between teachers and students make the teaching process more attractive and effective, students put more effort and attention on learning and that is bound to achieve better performance.

\section{Conclusion}

In general, CRS in large teaching classes is a viable solution that can alleviate a lot of realistic problems. While it is perfectly clear that the alone CRS as a teaching method is a part of the entire teaching process, full range application of CRS need to proper integrate all teaching aspects. Systems integration of CRS and campus educational IMS system is the need of curriculum management as well as the further key research directions.

\section{Acknowledgements}

Sichuan Agricultural University Teaching Reform Project, 15ZB0017 


\section{References}

[1] Y.H. Li: Clicker system and its Use in Large Class Teaching, the Chinese modern education equipment, 2012(13):9-10. (In Chinese)

[2] Z.L. Liu, Y. Luo and H.Y. Hu: Bilingual Teaching in Colleges and Universities, China University Teaching, (2012) .No. 5, P.58-60. (In Chinese)

[3] Crouch C H,Mazur E.Peer Instruction:Ten Years of Expenrience and Results.Am J Phys, 2001, 69(6): 970-977.

[4] M.H. Li, J.P. Zhang: Teaching Response System Present Situation and the Hotspot in the Research of the Application, China Sudio-visual Education, 2012(304):128-134. (In Chinese)

[5] Stelzer T, Selen M, Gladding G. SmartPhysics [M]. NY (W H Freeman \& Company, 2011).

[6] L.L. Chang: Application Strategy of Mobile Educational Equipment, Information Technology \& Informatization, (2015) .No.08, P.117. (In Chinese)

[7] Kondo, M. Mobile Assisted Language Learning in university EFL courses in Japan: developing attitudes and skills for self-regulated learning. ReCALL 24 (2012), p 169-187.

[8] Sana, F., Weston, T., Cepeda, N. J. (2013). Laptop multitasking hinders classroom learning for both users and nearby peers. Computers \& Education. Vol 62(2013), p 24-31.

[9] L.W. Wu: The Application of Classroom Response System in University classroom teaching, The Chinese modern education equipment, Vol. 169 (2013) No 9,p.21-22.(In Chinese)

[10] W.Y. Li, Z.Q. Pan: Problem-based Teaching Based on Immediate Feedback System, Physical engineering, Vol 58 (2012) No 7,P.193-195.(In Chinese)

[11]Q.P. Li: Mobile learning environment classroom response system (CRECloud) Design and Development (MS., GUANGXI TEACHERS EDUCATION UNIVERSITY), p.56, 58. (In Chinese)

[12]L. Song: Based on the Android Smartphone Classroom Feedback System Design and Implementation (MS., EAST CHINA NORMAL UNIVERSITY). (In Chinese) 